\title{
陆地棉亚红株突变性状的连锁遗传规律分析
}

陈旭升，狄佳春，马晓杰，刘新民

江苏省农业科学院经济作物研究所, 南京 210014

摘要: 以具有绿叶、花瓣红心的陆地棉、海岛棉与具有亚红株、无红心的陆地棉种质为试验材料, 通过经典遗 传学的二点测验分析了亚红株突变的连锁遗传规律; 结果显示, 测交群体 $(\mathrm{E} 083 \times$ B026) $\times$ 苏 $9701 、(B 026 \times$ E083) $\times$ 苏 9701 的平均交换值为 $1.35 \%$; 测交群体 $(\mathrm{E} 083 \times$ 海 7124) $\times$ 苏 $9701 、($ 海 7124×E083) $\times$ 苏 9701 的平均交换值 为 $2.94 \%$ 。同时, 用亚红株、无红心、棕絮与绿叶、红心、白絮种质杂交, 进行三点测验, 结果表明: 基因 $R s$ 在 $L c_{1} 、 R_{2}$ 之间; 基因 $R s$ 和 $L c_{1}$ 的遗传距离为 $42.21 \mathrm{cM}, R s$ 和 $R_{2}$ 的遗传距离为 $1.68 \mathrm{cM}$ 。当两对基因同时发生 双交换时, 相互干扰小, 符合系数达 0.79 。根据已知的基因遗传距离, 整合后绘制了遗传连锁图: Rs 基因位于 基因 $R_{2}$ 、 $L c_{1}$ 以及分子标记 NAU2863、NAU3735 和 NAU1048、BNL2634 之间; 其中 Rs 基因两侧的分子标记 NAU3735 和 NAU1048 与它的遗传距离分别为 $0.1 \mathrm{cM}$ 和 $0.2 \mathrm{cM}$ 。

关键词：陆地棉；亚红株突变；遗传距离；连锁图

\section{Analysis on linkage inheritance of sub-red plant mutant from upland cotton}

\author{
CHEN Xu-Sheng, DI Jia-Chun, MA Xiao-Jie, LIU Xin-Min \\ Institute of Industrial Crops, Jiangsu Academy of Agricultural Sciences, Nanjing 210014, China
}

\begin{abstract}
Analysis of linkage inheritance of sub-red plant, a natural mutant from upland cotton, was conducted by two-point test using parents Gossypium barbadense Hai7124 and G. hirsutum B026 both with petal spots and green leaves, and G. hirsutum E083 with normal white flowers and, sub-red plants. The average percentage of recombination was $1.35 \%$ when calculating test-cross combining populations derived from E083/B026//Su9701 and B026/E083//Su9701. The average percentage of recombination was 2.94\% when calculating test-cross combining populations derived from E083/Hai7124// $\mathrm{Su} 9701$ and Hai7124/E083//Su9701. Meanwhile, the genetic stocks having genotype $R s, L c_{1}, r_{2}$, and $r s, l c_{1}$, and $R_{2}$ were used in the three-point test, which demonstrated that the mutant gene Rs was located between genes $L c$ and $R_{2}$. The genetic distance between $R s$ and $L c_{1}$ was $42.21 \mathrm{cM}$, and $1.68 \mathrm{cM}$ between $R s$ and $R_{2}$. Coefficient of interference among $R_{2}, L c_{1}$, and Rs was 0.79 , indicating that the single cross between $R s$ and $R_{2}$ has less impact on the other single cross between $R s$ and $L c_{1}$. Based on known genetic distance around gene $R s$, the genetic linkage map was drawn. $R s$ is located between genes $L c_{1}$ and $R_{2}$, molecular marker NAU2863, NAU3735 and NAU3735, NAU1048. The genetic distances between $R_{s}$ and two markers NAU3735, NAU1048 are 0.1 and $0.2 \mathrm{cM}$, respectively.
\end{abstract}

Keywords: upland cotton; sub-red plant; genetic distance; linkage map

收稿日期: 2008-12-24; 修回日期: 2009-02-10 基金项目: 江苏省农业科学院科研基金项目(编号 : 6110812)资助

作者简介: 陈旭升(1965-), 男, 博士, 研究员, 研究方向：棉花遗传育种。E-mail: njcxs@126.com 
亚红株是国内新近发现的陆地棉自然突变体 ${ }^{[1]}$, 在提高光合效能上, 是潜在的优质种质资源 ${ }^{[2]}$ 。遗传 分析表明亚红株性状是受 1 对不完全显性基因控制 的质量性状; 等位性分析表明，亚红株显性基因与 已知的红株显性基因 $R_{1}$ 不存在复等位关系，它们是 两对位于不同染色体上的独立的非等位显性基因, 显示亚红株突变是有别于经典红株的新突变, 基因 符号定为 $R s^{[3]}$ 。

宋振云等 ${ }^{[4]}$ 选用 419 对 SSR 引物, 利用BSA (Bulked segregation analysis)法篮选由亚红株突变系 与常规陆地棉品系杂交构建的 $\mathrm{BC}_{1}$ 群体, 初步将突 变基因 $R s$ 定位在棉花第 7 染色体上; 并参阅前人已 定位的分子遗传图谱, 推测 $R s$ 基因与 $R_{2}$ 基因可能存 在紧密连锁。

经典遗传学已将 $R_{2} 、 L c_{1}$ 两基因定位在第 7 染色 体上。本研究利用特定的形态标记材料为亲本, 通 过经典遗传学的杂交、测交等方法, 以进一步确定 $R s 、 R_{2} 、 L c_{1} 3$ 个显性突变基因在第 7 染色体上的连 锁遗传距离。

\section{1 材料和方法}

\section{1 两点测验}

2006 年用绿叶、花瓣红心的陆地棉品系 B026、 海岛棉品系海 7124 分别与亚红株、无红心品系 E083 做正反交，得组合 E083× B026、B026× E083、E083× 海 7124、海 $7124 \times \mathrm{E} 083$ 。2007 年以纯隐性亲本“苏 9701” 做测交亲本, 配制测交组合如下: (E083× B026) $\times$ 苏 9701; (B026× E083) × 苏 9701; (E083×海 $7124) \times$ 苏 9701 ; (海 7124×E083) $\times$ 苏 9701 。

\section{2 三点测验}

2006 年以亚红株、无红心、棕絮品系 PD-17 与 绿叶、红心、白絮品系 B026 杂交。2007 年用绿叶、 无红心、白絮的纯隐性亲本“苏 9701” 做隐性测交, 配制组合(PD-17× B026)× 苏 9701, 2008 年用于大田 试验。

\section{3 大田性状调查记载}

2008 年营养钵育苗移栽, 种植 5 个测交分离群 体; 其中 4 个二点测交群体, 在开花期调查叶色绿叶、亚红; 花瓣红心——有、无。1 个三点测交
群体(PD-17× B026)× 苏 9701, 在开花期调查叶色绿叶、亚红; 花瓣红心—有、无; 在吐絮期调查絮 色—棕絮、白絮。

\section{4 计算方法}

交换值 $(\%)=$ 重组配子数/总配子数 $\times 100 \%$; 符 合系数 $=$ 实际双交换值/理论双交换值。

使用 Map Draw V2.1 软件绘制遗传连锁图。

\section{2 结果与分析}

\section{1 连锁遗传的二点测验}

绿叶、红心品系 B026、海 7124 与亚红株、无 红心品系 E083 杂交以及用隐性亲本苏 9701 做测交, 各群体性状分离(表 1)。

由表 1 可以看出: 正反交 $F_{1}$ 代均表现为亚红株、 花瓣红心，表明花瓣红心对无红心为显性、亚红株 对绿株为显性。4 个测交群体, 通过 $\chi^{2}$ 测验显示: 4 种表现型——亚红株花瓣红心：亚红株花瓣无红 心：绿株花瓣红心：绿株花瓣无红心的分离比例, 严重偏离了两对性状独立分离的 1：1：1：1理论 比例; 表明亚红株、花瓣红心两性状存在连锁遗传。 计算测交群体 $($ E083× B026)× 苏 9701、(B026× E083) $\times$ 苏 9701 的连锁交换值分别为 $1.01 \% 、 2.01 \%$ ，两测 交群体合并后的平均交换值为 $1.35 \%$; 计算测交群 体(E083×海 7124)×苏 9701、(海 7124×E083)×苏 9701 的连锁交换值分别为 $2.39 \% 、 3.46 \%$, 两测交群 体合并后的平均交换值为 $2.94 \%$ 。

\section{2 连锁遗传的三点测验}

以亚红株、无红心、棕絮品系 PD-17 与绿叶、 红心、白絮品系 B026 杂交, 用苏 9701 做隐性测交, 分离群体各种类型的表型(表 2)。

由表 2 可知, 个体数量最多的是亲型, 单交换 类型的数量较少, 个体数量最少的是双交换类型。 当发生双交换时，三基因 $R s 、 R R_{2} 、 L c_{1}$ 在染色体上的 排列方式不外乎以下 3 种: 第一种 $R_{2}$ 在 $R s 、 L c_{1}$ 之 间，第 2 种 $R s$ 在 $R_{2} 、 L c_{1}$ 之间，第三种 $L c_{1}$ 在 $R s$ 、 $R_{2}$ 之间; 而从本研究的两个杂交亲本的表现型判断, 只有第二种排列才会产生 $R_{2} R s_{-} l c_{1}$ 和 $r_{2} r s_{-} L c_{1}$ 的 双交换配子。因此，可以确定基因 $R s$ 在基因 $L c_{1}$ 、 $R_{2}$ 之间。 
表 1 亚红株与花瓣红心性状杂交后代的分离情况

\begin{tabular}{|c|c|c|c|c|c|c|c|}
\hline \multirow{2}{*}{ 世代 } & \multirow{2}{*}{ 亲本及组合 } & \multirow{2}{*}{$R s_{-} R_{2}$} & \multirow{2}{*}{$R s_{-} r_{2}$} & \multirow{2}{*}{$r s_{-} R_{2}$} & \multirow{2}{*}{$r s \_r_{2}$} & 理论比例 $\chi^{2}$ 值 & \multirow{2}{*}{ 交换值(\%) } \\
\hline & & & & & & $\mathrm{TC} \rightarrow 1: 1: 1: 1$ & \\
\hline $\mathrm{P}_{1}$ & B026 & / & / & 87 & / & 全部花瓣红心 & / \\
\hline $\mathrm{P}_{2}$ & 海 7124 & / & / & 26 & / & 全部花瓣红心 & / \\
\hline $\mathrm{P}_{3}$ & E083 & / & 65 & / & / & 全部亚红株 & l \\
\hline \multirow[t]{4}{*}{$\mathrm{F}_{1}$} & E083× B026 & 35 & l & / & l & $\begin{array}{l}\text { 全部亚红、 } \\
\text { 花瓣红心 }\end{array}$ & l \\
\hline & B026× E083 & 39 & l & l & l & $\begin{array}{l}\text { 全部亚红、 } \\
\text { 花瓣红心 }\end{array}$ & / \\
\hline & E083×海 7124 & 40 & l & l & l & $\begin{array}{l}\text { 全部亚红、 } \\
\text { 花瓣红心 }\end{array}$ & / \\
\hline & 海 $7124 \times \mathrm{E} 083$ & 21 & / & / & l & $\begin{array}{l}\text { 全部亚红、 } \\
\text { 花瓣红心 }\end{array}$ & 1 \\
\hline \multirow[t]{4}{*}{$\mathrm{TC}$} & $(\mathrm{E} 083 \times$ B026) $\times$ 苏 9701 & 1 & 325 & 261 & 5 & 582.14 & 1.01 \\
\hline & (B026× E083)× 苏 9701 & 2 & 154 & 139 & 4 & 277.01 & 2.01 \\
\hline & $($ E083×海 7124$) \times$ 苏 9701 & 1 & 120 & 125 & 5 & 227.90 & 2.39 \\
\hline & (海 $7124 \times \mathrm{E} 083) \times$ 苏 9701 & 3 & 131 & 120 & 6 & 226.25 & 3.46 \\
\hline
\end{tabular}

注: $R s_{-} R_{2}$ 代表“亚红株、花瓣红心”；Rs_r $r_{2}$ 代表“亚红株、花瓣无红心”；rs_R $R_{2}$ ：代表“绿株、花瓣红心”；rs_ $r_{2}$ : 代表“绿株、花瓣无 红心”。 $\chi_{0.05(3)}^{2}=7.81, \chi_{0.01(3)}^{2}=11.34$ 。

表 2 三点测交群体的性状分离情况

\begin{tabular}{|c|c|c|c|c|c|}
\hline 测交后代的表现型 & \multicolumn{3}{|c|}{$\mathrm{F}_{1}$ 配子种类 } & 株数 & 交换类型 \\
\hline 白心、亚红、棕絮 & $r_{2}$ & $R s$ & $L c_{1}$ & 232 & \multirow{2}{*}{ 亲型 } \\
\hline 红心、绿叶、白絮 & $R_{2}$ & $r s$ & $l c_{1}$ & 276 & \\
\hline 白心、亚红、白絮 & $r_{2}$ & $R s$ & $l c_{1}$ & 185 & \multirow{2}{*}{ 单交换 } \\
\hline 红心、绿叶、棕絮 & $R_{2}$ & $r s$ & $L c_{1}$ & 188 & \\
\hline 红心、亚红、棕絮 & $R_{2}$ & Rs & $L c_{1}$ & 2 & \multirow{2}{*}{ 单交换 } \\
\hline 白心、绿叶、白絮 & $r_{2}$ & rs & $l c_{1}$ & 8 & \\
\hline 红心、亚红、白絮 & $R_{2}$ & Rs & $l c_{1}$ & 0 & \multirow{2}{*}{ 双交换 } \\
\hline 白心、绿叶、棕絮 & $r_{2}$ & $r s$ & $L c_{1}$ & 5 & \\
\hline
\end{tabular}

基因间的交换值计算如下:

$R s$ 和 $R_{2} 、 L c_{1}$ 的双交换值 $=5 / 896 \times 100 \%=$ $0.56 \%$ 。

$R s$ 和 $L c_{1}$ 的单交换值 $=(185+188) / 896 \times 100 \%+$ $0.56 \%=42.21 \%$, 即 $R s$ 和 $L c_{1}$ 的遗传距离为 42.21 $\mathrm{cM}$ 。

$R s$ 和 $R_{2}$ 的单交换值 $=(8+2) / 896 \times 100 \%+0.56 \%$ $=1.68 \%$ ，即 $R s$ 和 $R_{2}$ 的遗传距离为 $1.68 \mathrm{cM}$ 。

根据 3 个显性基因的交换值, 并整合本项目组 有关 $R s$ 基因的分子标记定位结果 ${ }^{[4,5]}$, 绘制遗传连锁 图见图 1(保留 1 位小数点)。由图可知: $R s$ 基因位于 基因 $R_{2}$ 、 $L c_{1}$ 以及分子标记NAU2863、NAU3735 和 NAU1048、BNL2634 之间; 其中Rs 基因两侧的分子
标记NAU3735 和NAU1048 与它的遗传距离分别为 $0.1 \mathrm{cM}$ 和 $0.2 \mathrm{cM}$ 。这使得 $R s$ 基因的图位克隆成为可 能。

\subsection{3 个基因双交换的干扰分析}

当 3 个基因排列在一条染色体上时，如果相邻 两基因发生一个单交换以后, 那么在它毗邻发生第 二个单交换的机会就会减少，这种现象称干扰。对 于交换受干扰的程度，用符合系数表示，其值在 $0 \sim 1$ 之间。

计算本试验中基因 $R s$ 和 $R_{2} 、 L c_{1}$ 的理论双交换 值为 $0.4221 \times 0.0168 \times 100 \%=0.71 \%$; 符合系数 $=$ 实际双交换值/理论双交换值 $=0.56 / 0.71=0.79$ 。 


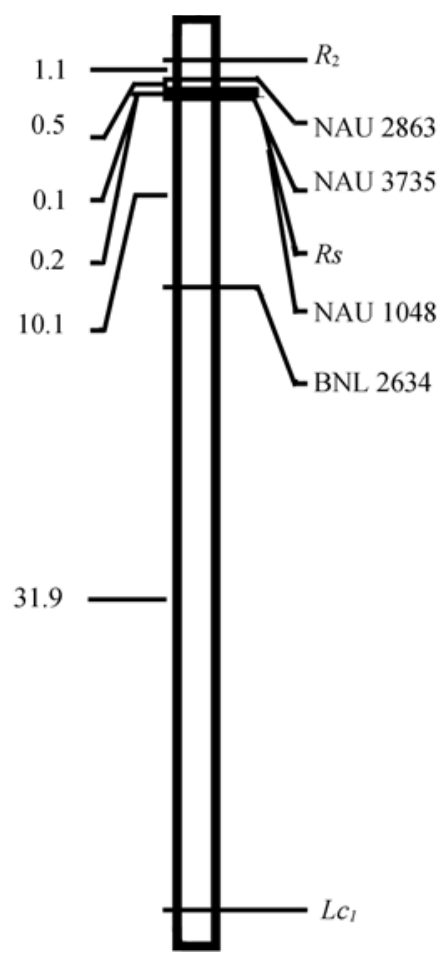

图 1 亚红株 $R s$ 、棕絮 $L c_{1}$ 、花畖辛红心 $R_{2}$ 三基因遗传连 锁图

可见，亚红株与红心、棕絮双交换的符合系数 较大，显示亚红株基因 $R s$ 与红心基因 $R_{2}$ 的单交换对 亚红株基因 $R s$ 与棕絮基因 $L c_{1}$ 的单交换干扰程度较 轻。究其原因是: $R s$ 与 $R_{2}$ 的距离很近, 仅 $1.68 \mathrm{cM}$; 而 $R s$ 与 $L c_{1}$ 的距离特远, 为 $42.21 \mathrm{cM}$ 。因此, 两者 同时发生交换时，彼此之间干扰很小。

\section{3 讨 论}

\section{1 关于 $R s$ 与 $L c_{1}$ 的连锁遗传}

由于基因 $R s$ 与 $L c_{1}$ 的遗传距离大, 所以采用经典 的卡方测验, 容易得出 $R s$ 与 $L c_{1}$ 呈完全独立遗传, 不 存连锁关系的结论 ${ }^{[3]}$ 。宋振云等 ${ }^{[4]}$ 首次通过分子标 记将 $R s$ 基因定位在第 7 染色体上, 而已知 $L c_{1}$ 也在第 7 染色体上, 因此推定 $R s$ 与 $L c_{1}$ 即使遗传距离较远, 也应该存在连锁关系。参阅陈旭升等 ${ }^{[3]}$ 发表在棉花 学报上的文章, 分析其原文“表 4”中的 TC群体, 显 示亲型的单株数要高于重组型单株数, 计算原 $\mathrm{TC}$ 群 体的 $R s$ 与 $L c_{1}$ 的交换 值为 $(26+32) /(37+26+32+42) \times$ $100 \%=42.3 \%$, 与本试验调查测交分离大群体的 $R s$ 与 $L c_{1}$ 交换值为 $42.2 \%$, 两者结果非常吻合。
3.2 经典遗传学定位与分子遗传学定位的相互 联系

关于 $R s$ 基因与 $R_{2}$ 基因的连锁距离，殷剑美等 ${ }^{[5]}$ 根据对 $R s$ 基因精细定位的结果，并参照 $\mathrm{Guo}$ 等 ${ }^{[6]}$ 发 $^{-}$ 表的遗传图谱, 推算出基因 $R s$ 与 $R_{2}$ 的连锁距离约 3.5 $\mathrm{cM}$ 。本研究根据(陆陆) $\mathrm{F}_{1} \times$ 陆的测交群体做二点测 定, 估测 $R s$ 与 $R_{2}$ 的平均遗传距离为 $1.35 \mathrm{cM}$; 根据 (陆陆) $\mathrm{F}_{1} \times$ 陆的测交群体做三点测定, 估测 $R s$ 和 $R_{2}$ 的遗传距离为 $1.68 \mathrm{cM}$, 均比分子定位推算的遗传 距离要小。然而, 用(海陆) $\mathrm{F}_{1} \times$ 陆的测交群体估测基 因 $R s$ 与 $R_{2}$ 的平均遗传距离为 $2.94 \mathrm{cM}$, 则与分子定 位推算的连锁距离基本相当; 而 Guo等 $\left.{ }^{[6]}\right]_{\frac{1}{1}}$ 表的分 子遗传图谱也是利用海陆杂交群体。通过上述比较 可以得出以下认知：(1)经典遗传学基因定位与分子 遗传学基因定位均显示 $R s$ 与 $R_{2}$ 的连锁距离较近, 表 现紧密的连锁遗传关系; 两者结果彼此印证, 充分 显示经典遗传学与分子遗传学在基因染色体定位上 的密切联系。(2)基因 $R s$ 与 $R_{2}$ 用(海陆) $\mathrm{F}_{1} \times$ 陆的测交 群体估测的遗传距离, 要大于(陆陆) $\mathrm{F}_{1} \times$ 陆的测交 群体估测的遗传距离, 这暗示海岛棉与陆地棉在某 些同源DNA区段的染色体长度可能存在差异; 在Rs 与 $R_{2}$ 两基因区段之间, 海岛棉是否存在比陆地棉更 多潜在的基因, 值得做进一步研究探索。

\section{参考文献(References):}

[1] 陈旭升. 陆地棉亚红株新突变体.中国棉花, 2004, 31(12): 19.

[2] 狄佳春, 殷剑美, 陈旭升, 肖松华, 许乃银, 刘剑光, 吴 巧娟. 陆地棉亚红株突变体光合特性初步研究. 江苏农 业科学, 2006, (2): 33-34.

[3] 陈旭升, 殷剑美, 狄佳春, 肖松华, 许乃银, 刘剑光, 吴 巧娟. 陆地棉亚红株突变的质量遗传规律研究. 棉花学 报, 2006, 18(4): 195-199.

[4] 宋振云, 杨志敏, 陈旭升. 陆地棉亚红株突变体基因的 初步定位. 作物学报, 2007, 33(3): 511-513.

[5] 殷剑美, 陈旭升, 肖松华, 许乃银, 狄佳春, 刘剑光, 吴 巧娟. 陆地棉亚红株突变体的研究进展及育种利用前 景. 江西农业学报, 2008, 20(10): 22-24.

[6] Guo WZ, Cai CP, Wang CB, Han ZG, Song XL, Wang K, Niu XW, Wang C, Lu KY, Shi B, Zhang TZ. A microsatellite-based, gene-rich linkage map reveals genome structure, function and evolution in Gossypium. Genetics, 2007, 176: 527-541. [DOI] 